\title{
Emerging therapies for acute traumatic spinal cord injury
}

\author{
Jefferson R. Wilson MD, Nicole Forgione PhD, Michael G. Fehlings MD PhD
}

$\mathrm{T}$ here are currently about 85000 Canadians living with spinal cord injuries, more than half of which are secondary to trauma. ${ }^{1}$ As the population ages, the incidence and prevalence of traumatic spinal cord injury are expected to increase, primarily as a result of fall-related injuries among older adults $^{2}$. Therefore, treating spinal cord injuries is relevant not only to spine surgeons and physiatrists, but also to the general clinician who will increasingly encounter such patients in the emergency department or family practice.

Here, we review relevant pathophysiology and recent evidence pertaining to the medical, surgical and cellular-based treatment of acute traumatic spinal cord injury. Most of the identified pharmacologic studies were randomized trials or early phase nonrandomized prospective studies. Research relating to the remaining topics was predominately observational in design (Box 1).

\section{What mechanisms underlie neural injury and repair?}

The initial trauma, or primary injury to the spinal cord, starts a sequence of pathological events collectively referred to as secondary injury. These secondary mechanisms begin within seconds of the primary injury and continue for several weeks thereafter, leading to an expanded region of tissue destruction (Figure 1). The initial disruption of the spinal cord vasculature leads to the development of microhemorrhages in the grey and white matter, interstitial edema and the release of coagulation factors and vasoactive amines. $^{3}$ These events promote thrombosis and vasospasm of the microvasculature of the spinal cord causing tissue hypoxia and impaired neuronal homeostasis. At the cellular level, impairments include ionic imbalance, peroxidation of membrane lipids, formation of free radicals and release of toxic levels of the excitatory neurotransmitter glutamate. ${ }^{4}$ Neuroprotective agents act to mitigate secondary injury mechanisms to reduce the extent of neural damage.

The regenerative capacity of the neurons of the central nervous system (CNS) is severely limited compared with neurons in the peripheral nervous system, largely because of the production of inhibitory molecules that thwart axonal growth, preventing regeneration of injured nerve tracts. Nogo is a family of inhibitory proteins that bind to the Nogo receptor found on regenerating axons. ${ }^{5}$ This binding leads to the activation of the Rho pathway, causing inhibition of both axonal growth and neuronal cytoskeletal development. ${ }^{6}$ In contrast to neuroprotective therapies, which limit the extent of acute neural injury, neuroregenerative therapies facilitate neuronal regrowth by several mechanisms, including the blockade of these inhibitory pathways.

\section{What supportive and surgical management is effective?}

Historically, it was common for patients with spinal injuries to be placed in unmonitored beds on hospital wards for prolonged periods while elements of the bony injury healed. This approach has been supplanted by aggressive medical and surgical methods focused on maintaining cord perfusion, avoiding complications, decompressing the spinal cord and restoring spinal stability.

\section{Medical support}

The negative consequences of hypotension on the injured CNS are well established. ${ }^{8}$ There is consistent evidence that avoiding hypotension and
Competing interests: None declared.

This article has been peer reviewed.

Correspondence to: Michael G. Fehlings, Michael.Fehlings@uhn.on.ca

CMAJ 2013. DOI:10.1503 /cmaj.121206

\section{- Ker pOINTS}

- Hemodynamic support to maintain mean arterial pressure at 85$90 \mathrm{mmHg}$ and monitoring in an intensive care unit for the first week after spinal cord injury are recommended.

- Decompressive surgery within 24 hours after injury has been shown to be safe and feasible; in prospective nonrandomized trials, it has been associated with improved rates of neurologic recovery.

- Intravenous methylprednisolone has been used as a neuroprotective strategy based on limited evidence, but this is not a standard of care and may be associated with an increased risk of complications.

- The safety of cellular transplantation in human spinal cord injury is under study in early phase clinical trials, but is currently purely an investigational therapy

- Early phase clinical trials are investigating potential regenerative (e.g., Rho and Nogo inhibitors) and neuroprotective (e.g., riluzole, minocycline, hypothermia) therapies. 
maintaining aggressive blood pressure targets during the acute phases after injury improves neurologic recovery and reduces mortality. ${ }^{9}$ Based on existing, largely retrospective data, the American Association of Neurological Surgeons recommends that patients' mean arterial pressure be maintained at $85-90 \mathrm{mmHg}$ for the first 7 days after injury. ${ }^{10}$ When volume replacement is inadequate to achieve this goal, intravenous vasopressor medications may be introduced.

Patients, particularly those with severe cervical injuries, should receive treatment in an intensive care unit (ICU) with continuous cardiac, hemodynamic and respiratory monitoring for the first 7-14 days after injury. In observational studies, the standardized admission of patients with spinal injuries to an ICU has been associated with reduced mortality and morbidity, in addition to improved neurologic recovery. ${ }^{11}$

\section{Surgical decompression}

The preclinical literature provides a strong biological imperative to decompress the spinal cord early after injury. ${ }^{12}$ In spite of compelling laboratory findings, for many years, surgeons were reluctant to operate acutely owing to concerns that perioperative hemodynamic changes would compromise cord perfusion. ${ }^{13}$ In addition, until the proliferation of instrumented spinal fixation techniques in the 1990s, decompression meant further destabilizing an already unstable spine.

Retrospective studies provide conflicting results as to the effect of early surgery on neurologic recovery, but all have shown early decompression to be safe. ${ }^{14}$ The Surgical Timing in Acute Spinal Cord Injury Study (STASCIS), ${ }^{15}$ a prospective, multicentre, nonrandomized cohort study, compared 313 patients who underwent either early $(<24 \mathrm{~h}$ after injury) or late $(\geq 24 \mathrm{~h}$ after injury) surgical decompression. Early surgery was associated with better neurologic recovery at 6 months as defined by a 2-grade improvement in the American Spinal Injury Association impairment scale (odds ratio [OR] $2.57,95 \%$ confidence interval [CI] 1.11 to 5.97 ),

\section{Box 1: Evidence used in this review}

We performed a comprehensive literature search of MEDLINE for the key words "spinal cord injury" and the medical subheading "treatment." We limited the search to clinical articles published between 1980 and 2012 in English journals. We excluded studies involving animals, review articles and case reports. We supplemented this strategy by searching the Cochrane Database of Systematic Reviews for the term "spinal cord injury." We identified and reviewed 401 abstracts for relevance to the topic. We selected 45 abstracts for which we obtained the full-text version to use as the basis for this review. In addition, we reviewed the 2002 American Association of Neurological Surgeons/Congress of Neurological Surgeons cervical spinal cord injury consensus guidelines, as well as the Consortium for Spinal Cord Medicine 2008 spinal cord injury early acute management clinical practice guidelines. with no increase in acute complications compared with late surgery $(24.2 \%$ v. $30.5 \%, p=$ $0.21)$. These results validate those of recent consensus surveys suggesting surgeon preference toward early decompression. ${ }^{16}$

In the specific case of dislocation of the cervical spine, rapid closed reduction of the spine using skeletal traction remains a valid treatment option. In this case, surgery is performed after closed reduction to re-establish spinal stability.

\section{Therapeutic hypothermia}

Preclinical studies have suggested that cooling mitigates secondary injury mechanisms. ${ }^{17}$ Initial clinical studies involving direct cooling of the cord during surgery failed to show any benefit. However, a recent phase I trial investigated the acute use of modest $\left(33^{\circ} \mathrm{C}\right)$ systemic intravascular hypothermia. ${ }^{18}$ Complications did not differ between the 14 patients receiving the treatment and the 14 patients to whom they were matched in the control group. At 1-year followup, 6 of 14 patients in the treatment group $(42.9 \%)$ converted from complete (no motor or sensory function below the level of injury) to incomplete (motor or sensory function present below the level of injury) status (3/14 [21.4\%] of patients in the control group showed the same degree of recovery), which compares favourably with a neurologic recovery rate of $20 \%$ reported in the literature. Although there is currently insufficient evidence to support the use of systemic hypothermia, a multicentre efficacy trial exploring this therapy is being planned.

\section{What drugs have been evaluated for treating spinal cord injury?}

To date, 5 pharmacologic therapies have been evaluated in phase III trials (Table 1). ${ }^{19-23}$ None of them have become standard of care.

\section{Neuroprotective agents}

\section{Methylprednisolone sodium succinate}

Methylprednisolone, which attenuates the peroxidation of membrane lipids and post-traumatic inflammation, has consistently been associated with improved neurobehavioural outcomes in preclinical studies. ${ }^{24}$ However, the use of methylprednisolone in the clinical setting remains controversial. The most recent Cochrane review pooled the results of 3 studies (meta-analyses) and found no effect for a high-dose 24-hour infusion of methylprednisolone in terms of motor recovery at 6 months (weighted mean difference $0.85,95 \% \mathrm{CI}-1.79$ to 3.49$).{ }^{25}$ However, when 
started within 8 hours after injury, methylprednisolone was associated with an additional 4point improvement in NASCIS motor score (weighted mean difference 4.06, 95\% CI 0.58 to 7.55). ${ }^{25}$ Trends toward increased rates of gastrointesinal hemorrhage (relative risk [RR] 2.18, $95 \%$ CI 0.80 to 5.93 ) and wound infections
(RR 2.11, 95\% CI 0.81 to 5.49) were seen among patients receiving methylprednisolone. ${ }^{25}$ Critics of the drug cite these complications, as well as the use of subgroup analyses to prove effect, as arguments against its use. ${ }^{26}$ Balancing the available evidence, consensus guidelines recommend that 24-hour infusion of methylpred-
A

Mechanisms

Primary injury:

- Compression

- Laceration

- Distraction

- Shearing

Immediate:

- Hemorrhage

- Decreased ATP

- Increased lactate

concentration (acidosis)

Early acute:

- Vasogenic edema

- Microvessel vasospasm

- Thrombosis

- Ion imbalance

- Loss of sodium gradient

- Release of neurotoxic opioids

- Inflammation

- Lipid peroxidation

- Glutamatergic excitoxicity

- Cytotoxic edema

- Formation of free radicals

\section{Subacute:}

- Microglial stimulation

- Macrophage activation

- Apoptosis
B

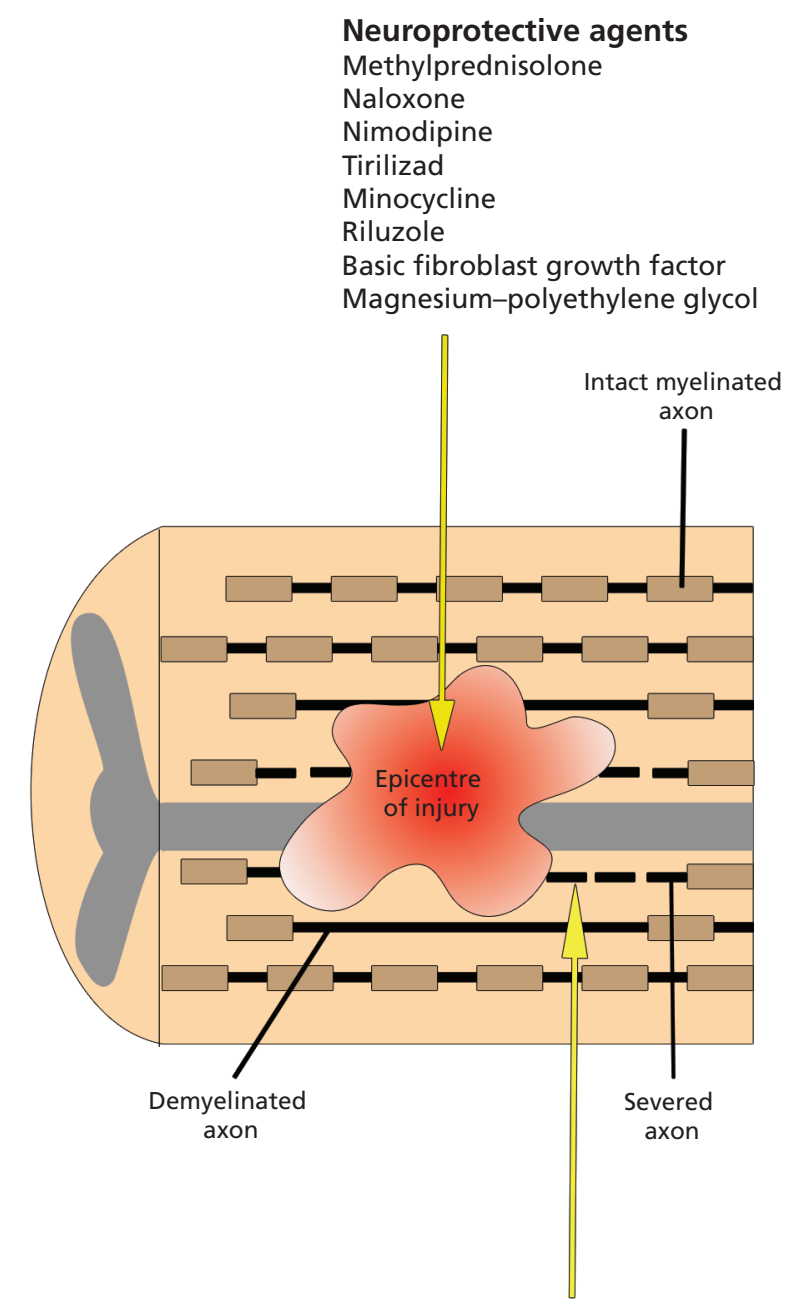

Neuroregenerative agents GM-1 (Sygen)

Cethrin

Anti-Nogo

Chondroitinase $A B C$

Neural stem cells

Figure 1: (A) Primary and secondary mechanisms of injury determining the final extent of spinal cord damage. The primary injury event starts a pathobiological cascade of secondary injury mechanisms that unfold in different phases within seconds of the primary trauma and continuing for several weeks thereafter. (B) Longitudinal section of the spinal cord after injury. The epicentre of the injury progressively expands after the primary trauma as a consequence of secondary injury events. This expansion causes an increased region of tissue cavitation and, ultimately, worsened long-term outcomes. Within and adjacent to the injury epicentre are severed and demyelinated axons. The neuroprotective agents listed act to subvert specific secondary injuries and prevent neural damage, while the neuroregenerative agents act to promote axonal regrowth once damage has occurred. ATP = adenosine triphosphate. 
nisolone, started within 8 hours after injury, is a treatment option that should only be undertaken with knowledge of the potential complications. ${ }^{27}$

\section{Other medications}

Other treatments studied for neuroprotection include naloxone, an opioid antagonist that blocks the neurotoxic effects of the endogenous opioid dynorphin $\mathrm{A} ;{ }^{19,28}$ tirilazad, a nonglucocorticoid 21-aminosteroid developed to inhibit the peroxidation of neuronal membranes; ${ }^{22}$ and nimodipine, a calcium-channel blocker that prevents calcium-dependent activation of destructive cellular enzymes and presynaptic glutamate release. ${ }^{21,29}$ Although each of these agents showed efficacy in animals studies, clinical trials of naloxone versus placebo, ${ }^{19}$ tirilazad versus methylprednisolone ${ }^{22}$ and nimodipine versus placebo $^{21}$ have all failed to show differences in motor recovery.

\section{Neuroregenerative agents}

\section{GM-1 (Sygen)}

Gangliosides are complex glycolipid molecules comprising an important structural component of neuronal membranes. Laboratory studies have shown that gangliosides can enhance axonal

Table 1: Pharmacologic agents evaluated in phase III trials for acute treatment of traumatic spinal cord injury

\begin{tabular}{|c|c|c|c|}
\hline Drug & Purported mechanism & $\begin{array}{l}\text { No. of RCTs } \\
\text { evaluating drug }\end{array}$ & Evidence for use \\
\hline $\begin{array}{l}\text { Methylprednisolone } \\
\text { sodium succinate }\end{array}$ & $\begin{array}{l}\text { - Attenuates peroxidation of the } \\
\text { neuronal membrane } \\
\text { - Reduces TNF- } \alpha \text { release } \\
\text { - Improves perfusion of spinal cord } \\
\text { - Reduces influx of neuronal calcium }\end{array}$ & $\begin{array}{l}3 \text { (evaluating } \\
\text { high-dose } 24-h \\
\text { infusion v. } \\
\text { placebo) } \\
1 \text { (evaluating } \\
\text { high-dose } 48-h \\
\text { infusion v. high- } \\
\text { dose } 24-h \\
\text { infusion) }^{22}\end{array}$ & 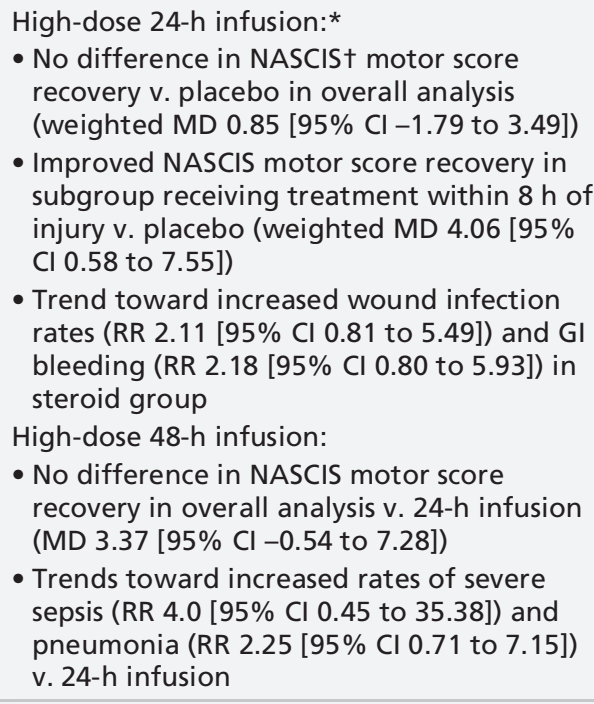 \\
\hline Naloxone & $\begin{array}{l}\text { - Blocks the neurotoxic effects of the } \\
\text { endogenous opioid dynorphin A }\end{array}$ & 1 (v. placebo) ${ }^{19}$ & $\begin{array}{l}\text { - No difference in NASCIS motor score } \\
\text { recovery between treatment and placebo } \\
\text { groups }\end{array}$ \\
\hline Nimodipine & $\begin{array}{l}\text { - L-type calcium-channel blocker } \\
\text { - Prevents activation of calcium- } \\
\text { dependent apoptotic enzymes and } \\
\text { blocks presynaptic release of } \\
\text { glutamate }\end{array}$ & 1 (v. placebo) ${ }^{21}$ & $\begin{array}{l}\text { - No difference in motor neurologic status } \\
\text { between treatment (ASIA motor score } 67 \\
\text { [95\% CI } 50 \text { to } 95] \text { ) and placebo groups } \\
\text { (ASIA motor score } 72 \text { [95\% CI } 50 \text { to } 94] \text { at } \\
1 \text { year }\end{array}$ \\
\hline Tirilazad mesylate & $\begin{array}{l}\text { - Attenuates peroxidation of neuronal } \\
\text { membrane }\end{array}$ & $\begin{array}{l}1 \text { (v. 24-h infusion } \\
\text { of methylpred- } \\
\text { nisolone) }\end{array}$ & $\begin{array}{l}\text { - No difference in NASCIS motor score } \\
\text { recovery between tirilazad and } 24-\mathrm{h} \\
\text { infusion of methylprednisolone } \\
\text { - No placebo-controlled evaluation available }\end{array}$ \\
\hline $\begin{array}{l}\text { GM-1 ganglioside } \\
\text { (Sygen) }\end{array}$ & $\begin{array}{l}\text { - Important component of CNS } \\
\text { neuronal membranes } \\
\text { - Facilitates regrowth and } \\
\text { regeneration of axons } \\
\text { - Several neuroprotective properties }\end{array}$ & 1 (v. placebo) ${ }^{23}$ & $\begin{array}{l}\text { - No difference in marked neurologic } \\
\text { recovery between treatment and placebo } \\
\text { groups as defined by at least a 2-grade } \\
\text { improvement in modified Benzel scale§ } \\
\text { grade }\end{array}$ \\
\hline $\begin{array}{l}\text { rdinal score between } \\
\text { rginal score between } \\
\text { rdinal scale between }\end{array}$ & ining the results of 3 studies. & n the right side & $\begin{array}{l}\text { nervous system, MD = mean difference, NASCIS = } \\
\text { necrosis factor. } \\
\text { body. A higher score suggests better motor function. } \\
\text { oody. A higher score suggests better motor function. }\end{array}$ \\
\hline
\end{tabular}


regeneration after injury. ${ }^{30}$ In addition, a variety of neuroprotective effects have been attributed to these compounds. However, a randomized placebo-controlled trial of the ganglioside compound GM-1 (Sygen) involving 760 patients $^{23}$ reported no difference in the proportion of patients achieving marked neurologic recovery at 6 months, although quantitative results were not presented.

\section{What drugs are in development for treating spinal cord injury?}

Several neuroprotective and neuroregenerative agents targeting specific pathological mechanisms are currently in the midst of clinical translation. Although promising, these agents have yet to show efficacy in phase III trials.

\section{Neuroprotective agents}

\section{Riluzole}

Riluzole is a sodium-channel blocker approved by the US Food and Drug Administration and Health Canada for the treatment of amyotrophic lateral sclerosis (ALS), in which it reduces motor neuron degeneration, thereby prolonging survival. ${ }^{31}$ In preclinical models of spinal cord injury, riluzole mitigates secondary injury by blocking pathological activation of sodium channels and reducing the release of neuronal glutamate. ${ }^{4} \mathrm{~A}$ phase I/II trial evaluating the safety and pharmacokinetics of riluzole for injuries in humans began in 2010 and was completed in January 2012, with full results awaiting publication..$^{32,33}$

\section{Minocycline}

Minocycline, a chemically modified form of tetracycline, has shown to be neuroprotective in animal injury models, although its exact mechanisms of action remain incompletely understood. ${ }^{34}$ Its use in other clinical conditions, such as acne, shows it has a favourable safety profile in humans. In a randomized placebo-controlled phase II trial, minocycline was associated with a trend toward improved motor recovery at 1 year (difference in American Spinal Injury Association motor score 6 points, $95 \% \mathrm{CI}-3$ to $14, p=0.20) .{ }^{35} \mathrm{~A}$ single case of transiently elevated serum transaminases was the only drug-related complication reported.

\section{Basic fibroblast growth factor}

Injection of basic fibroblast growth factor has been shown to improve functional and respiratory parameters in animal injury models, presumably by reducing glutamate-mediated excitotoxicity. ${ }^{36}$ A recombinant version of this molecule is the subject of a phase I/II trial currently recruiting patients.

\section{Neuroregenerative agents}

\section{Cethrin}

BA-210 is a bacterial-derived toxin that inhibits the Rho pathway of inhibitory proteins and promotes axonal growth in vitro. When combined with a biohemostatic adhesive, BA-210 forms a permeable paste called Cethrin that is applied to the dura of the spinal cord postinjury. Based on documentation of preclinical efficacy, a phase I/IIa trial was undertaken during which 1 of 2 Cethrin dosages was applied to the dura during surgery in 48 patients with complete injuries. ${ }^{6}$ No serious complications were attributed to Cethrin at 1-year follow-up. Furthermore, among patients receiving doses of 1 and $3 \mathrm{mg}$, those with cervical injuries showed improvement on the American Spinal Injury Association motor score (mean of 27 points for patients in the $1 \mathrm{mg}$ group and 21 points for patients in the $3 \mathrm{mg}$ group). Such improvements compare favourably to the 10 points of motor recovery reported for similar patients in historical case series.

\section{Anti-Nogo}

Nogo-A is a protein that has been shown to block axonal growth in the human $\mathrm{CNS}^{37}$ AntiNogo is a monoclonal antibody engineered to target Nogo-A and promote neural regeneration. ${ }^{38}$ This drug is currently in the early stages of clinical investigation.

\section{What is the current status of cellular transplantation as a treatment option?}

The transplantation of stem cells and autologous non-stem cells has been intensively studied in preclinical injury models. Various cellular subtypes have been used for this purpose, seeking optimal balance of the one or more key mechanisms through which each is theorized to act (release of growth-promoting trophic factors, environmental modification [i.e., reduction of scar or inflammation] and cellular replacement). In preclinical studies, cellular transplantation, either alone or in combination with other therapies, has been associated with enhanced neurobehavioural recovery, with no single cellular subtype showing superiority ${ }^{39}$ Although prematurely used to treat patients with spinal injuries in several countries, no study has established efficacy for the transplantation of any cellular line. However, in the existing early phase trials, major 
adverse events related to transplantation have been rare. When interpreting the results of clincal studies involving transplantation of cellular subtypes (Table 2), ${ }^{40-48}$ it is important to consider that, independent of treatment, most patients will undergo some natural neurologic recovery that will plateau 4-6 months after injury. For noncontrolled studies in which patients receive transplants before this plateau, it is impossible to discern whether improvements are related to treatment or simply to the patient's natural recovery potential. For this reason, results must be interpreted with caution.

Table 2: Summary of types of cells and the results of associated published or ongoing clinical research into their use for the treatment of spinal cord injury

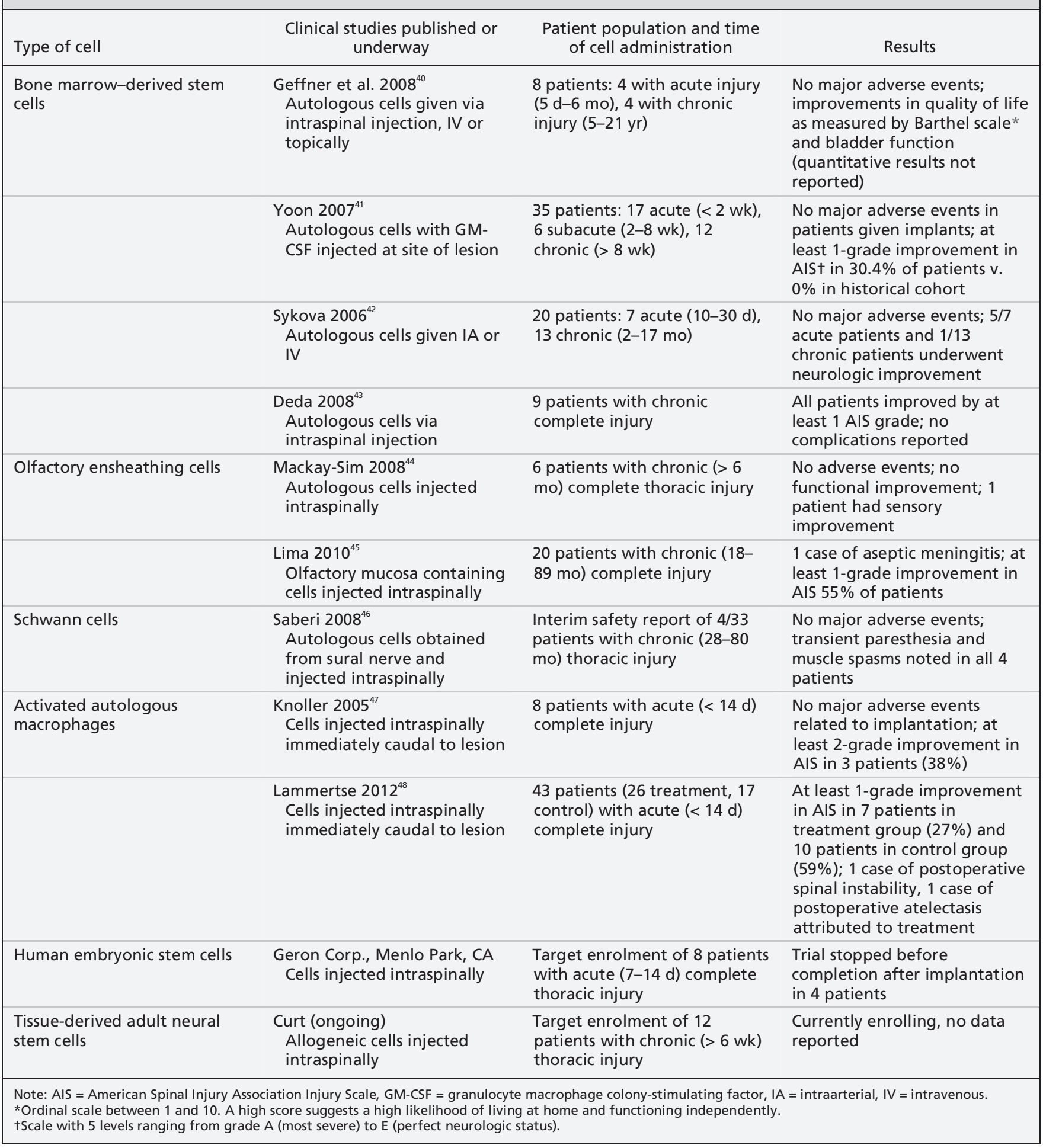


Overall, cellular transplantation is purely an investigational therapy, which should currently only be undertaken in the context of clinical trials.

\section{Future directions}

Box 2 provides a fictional case in which the results of this review are applied in clinical practice. Recent laboratory work has identified other promising therapies yet to appear on the clinical landscape. Chondroitinase ABC is a bacterialderived enzyme that has shown beneficial effects in rodent injury models by degrading elements of the glial scar preventing post-traumatic axonal growth. ${ }^{49}$ When combined with magnesium, the hydrophilic polymer polyethylene glycol has shown neuroprotective properties in animal models by preserving neuronal membrane integrity. ${ }^{50}$ Both of these treatments appear poised for eventual translation to the clinic.

More recently, several groups have begun to investigate the role of nanomedicine in promoting neuroprotection and neuroregeneration after injury. ${ }^{51}$ Cerium oxide and gold nanoparticles have shown positive results both in vitro and in

Box 2: Applying the results of this review in clinical practice (fictional case)

A 25-year-old unrestrained male driver presents to the emergency department 30 minutes after a high-speed motor vehicle accident. His mean arterial pressure is $65 \mathrm{mmHg}$. Neurological examination shows a lack of motor or sensory function below $\mathrm{C} 5$. Subsequent computed tomography and magnetic resonance imaging show a fracture and dislocation of the cervical spine causing compression of the spinal cord. No other major injuries are identified.

Immediate attention should be placed on optimizing oxygenation and hemodynamic status, as well as on ensuring immobilization of the craniospinal axis. A mean arterial pressure of $85-90 \mathrm{mmHg}$ should be achieved and maintained for the first week after injury using volume resuscitation, augmented with vasopressors as needed. Consultation with the spine surgery service should occur as early as possible to evaluate the patient's suitability for immediate decompression and stabilization surgery. Although the patient presents within 8 hours after his injury, methylprednisolone is not standard therapy; rather, it could lead to additional complications. The patient should be admitted to an intensive care unit with continuous cardiac, hemodynamic and respiratory monitoring for the first 1-2 weeks after his injury. Although several additional treatments such as pharmacologic agents, systemic hypothermia and cellular transplantation appear promising in early phase trials, none are currently recommended for routine clinical use. vivo. Finally, apart from pharmacologic therapies, researchers are in the early phases of investigating neuromodulatory approaches such as epidural spinal cord stimulation to aid rehabilitation efforts during the chronic phases after injury. ${ }^{52}$ Although only described in the form of case reports, such approaches appear promising and may someday augment the benefits contributed by acute therapeutics to maximize patients' long-term potential for recovery.

\section{References}

1. Noonan VK, Fingas M, Farry A, et al. The incidence and prevalence of spinal cord injury in Canada: a national perspective. Neuroepidemiology 2012;38:219-26.

2. Farry A, Baxter D. The incidence and prevalence of spinal cord injury in Canada: overview and estimates based on current evidence. Vancouver (BC): Rick Hansen Institute and Urban Futures; 2010. Available: www.urbanfutures.com/reports/Report \%2080.pdf (accessed 2011 June 15).

3. Tator $\mathrm{CH}$, Fehlings MG. Review of the secondary injury theory of acute spinal cord trauma with emphasis on vascular mechanisms. J Neurosurg 1991;75:15-26.

4. Schwartz G, Fehlings M. Secondary injury mechanisms of spinal cord trauma: a novel therapeutic approach for the management of secondary pathophysiology with the sodium channel blocker riluzole. Prog Brain Res 2002;137:177-90.

5. Fitch MT, Silver J. CNS injury, glial scars, and inflammation: inhibitory extracellular matrices and regeneration failure. Exp Neurol 2008;209:294-301.

6. Fehlings MG, Theodore N, Harrop J, et al. A phase I/IIa clinical trial of a recombinant Rho protein antagonist in acute spinal cord injury. J Neurotrauma 2011;28:787-96.

7. Wilson JR, Fehlings MG. Emerging approaches to the surgical management of acute traumatic Spinal Cord Injury. Neurotherapeutics 2011;8:187-94

8. Chesnut RM, Marshall L, Klauber M, et al. The role of secondary brain injury in determining outcome from severe head injury. J Trauma 1993;34:216-22.

9. Levi L, Wolf A, Belzber H. Hemodynamic parameters in patients with acute cervical cord trauma: description, intervention, and prediction of outcome. Neurosurgery 1993;33:1007-10167.

10. Blood pressure management after acute spinal cord injury. Neurosurgery 2002;50:S58-62.

11. Management of acute spinal cord injuries in an intensive care unit or other monitored setting. Neurosurgery 2002; (Suppl 3): S51-7.

12. Furlan JC, Noonan V, Cadotte DW, et al. Timing of decompressive surgery of spinal cord after traumatic spinal cord injury: an evidence-based examination of pre-clinical and clinical studies. J Neurotrauma 2011;28:1371-99.

13. Bedbrook GM, Sedgley GI. The management of spinal injuries — past and present. Int Rehabil Med 1980;2:45-61.

14. Fehlings MG, Perrin RG. The timing of surgical intervention in the treatment of spinal cord injury: a systematic review of recent clinical evidence. Spine (Phila Pa 1976). 2006;31(Suppl 11):S28-35; discussion S6.

15. Fehlings MG, Vaccaro A, Wilson J, et al. Early versus delayed decompression for traumatic cervical spinal cord injury: results of the Surgical Timing in Acute Spinal Cord Injury Study (STASCIS). PLoS ONE 2012;7:e32037.

16. Fehlings MG, Rabin D, Sears W, et al. Current practice in the timing of surgical intervention in spinal cord injury. Spine 2010; 35:S166-73.

17. Lo TP Jr, Cho KS, Garg MS, et al. Systemic hypothermia improves histological and functional outcome after cervical spinal cord contusion in rats. J Comp Neurol 2009;514:433-48.

18. Levi AD, Casella G, Green BA, et al. Clinical outcomes using modest intravascular hypothermia after acute cervical spinal cord injury. Neurosurgery 2010;66:670-7.

19. Bracken MB, Shepard M, Collins W, et al. A randomized, controlled trial of methylprednisolone or naloxone in the treatment of acute spinal-cord injury. Results of the Second National Acute Spinal Cord Injury Study. N Engl J Med 1990;322:1405-11.

20. Otani K, Abe H, Kadoya S. Beneficial effects of methylprednisolone sodium succinate in the treatment of acute spinal cord injury. Sekitsy Sekizui 1994;7:633-47.

21. Petijean ME, Pointillart V, Dixmerias F, et al. Medical treatment 
of spinal cord injury in the acute stage. Ann Fr Anesth Reanim 1998; 17:115-22.

22. Bracken MB, Shepard M, Holford T, et al. Administration of methylprednisolone for 24 or 48 hours or tirilazad mesylate for 48 hours in the treatment of acute spinal cord injury. Results of the Third National Acute Spinal Cord Injury Randomized Controlled Trial. National Acute Spinal Cord Injury Study. JAMA 1997;277:1597-604

23. Geisler FH, Coleman W, Grieco G, et al. The Sygen multicenter acute spinal cord injury study. Spine 2001;26:S87-98.

24. Braughler JM, Hall E. Effects of multi-dose methylprednisolone sodium succinate administration on injured cat spinal cord neurofilament degradation and energy metabolism. J Neurosurg 1984;61:290-5.

25. Bracken MB. Steroids for acute spinal cord injury. Cochrane Database Syst Rev 2012;1:CD001046.

26. Hurlbert RJ. Methylprednisolone for acute spinal cord injury: an inappropriate standard of care. J Neurosurg 2000;93:1-7.

27. Hugenholtz H, Cass D, Dvorak M. High-dose methylprednisilone for acute closed spinal cord injury - only a treatment option. Can J Neurol Sci 2002; 3:227-35.

28. Baskin DS, Simpson RK Jr, Browning JL, et al. The effect of long-term high-dose naloxone infusion in experimental blunt spinal cord injury. J Spinal Disord 1993;6:38-43.

29. Fehlings MG, Tator CH, Linden RD. The effect of nimodipine and dextran on axonal function and blood flow following experimental spinal cord injury. J Neurosurg 1989;71:403-16.

30. Bose B, Osterholm J, Kalia M. Ganglioside-induced regeneration and reestablishment of axonal continuity in spinal cordtransected rats. Neurosci Lett 1986;63:165-9.

31. Miller RG, Mitchell JD, Lyon M. Riluzole for amyotrophic lateral sclerosis (ALS)/motor neuron disease (MND). Cochrane Database Syst Rev 2007;(1):CD001447.

32. Fehlings MG, Wilson JR, Frankowski RF, et al. Riluzole for the treatment of acute traumatic spinal cord injury: rationale for and design of the NACTN Phase I Clinical Trial. J Neurosurg Spine 2012;17:151-6.

33. Grossman RG, Fehlings MG, Frankowski RF, et al., editors. A phase I multicenter trial to investigate the safety and pharmacokinetics profile of riluzole in the treatment of traumatic spinal cord injury. Proceedings of the Society for Neuroscience 12 meeting; 2012 Oct. 14; New Orleans.

34. Festoff BW, Ameenuddin S, Arnold PM, et al. Minocycline neuroprotects, reduces microgliosis, and inhibits caspase protease expression early after spinal cord injury. J Neurochem 2006;97:1314-26.

35. Casha S, Zygun D, McGowan M, et al. Results of a phase II placebo-controlled randomized trial of minocylcine in acute spinal cord injury. Brain 2012;135:1224-36.

36. Teng YD, Mocchetti I, Taveira-DaSilva AM, et al. Basic fibroblast growth factor increases long-term survival of spinal motor neurons and improves respiratory function after experimental spinal cord injury. J Neurosci 1999;19:7037-47.

37. Spillmann AA, Bandtlow CE, Lottspeich F, et al. Identification and characterization of a bovine neurite growth inhibitor (bNI220). J Biol Chem 1998;273:19283-93.

38. Freund P, Wannier T, Schmidlin E, et al. Anti-Nogo-A antibody treatment enhances sprouting of corticospinal axons rostral to a unilateral cervical spinal cord lesion in adult macaque monkey. J Comp Neurol 2007;502:644-59.

39. Sahni V, Kessler JA. Stem cell therapies for spinal cord injury. Nat Rev Neurol 2010;6:363-72.
40. Geffner LF, Santacruz P, Izurieta M, et al. Administration of autologous bone marrow stem cells into spinal cord injury patients via multiple routes is safe and improves their quality of life: comprehensive case studies. Cell Transplant 2008;17:1277-93.

41. Yoon SH, Shim YS, Park YH, et al. Complete spinal cord injury treatment using autologous bone marrow cell transplantation and bone marrow stimulation with granulocyte macrophage-colony stimulating factor: phase I/II clinical trial. Stem Cells 2007;25: 2066-73.

42. Syková E, Homola A, Mazanec R, et al. Autologous bone marrow transplantation in patients with subacute and chronic spinal cord injury. Cell Transplant 2006;15:675-87.

43. Deda H, Inci MC, Kurekci AE, et al. Treatment of chronic spinal cord injured patients with autologous bone marrow-derived hematopoietic stem cell transplantation: 1-year follow-up. Cytotherapy 2008;10:565-74.

44. Mackay-Sim A, Feron F, Cochrane J, et al. Autologous olfactory ensheathing cell transplantation in human paraplegia: a 3-year clinical trial. Brain 2008;131:2376-86.

45. Lima C, Escada P, Pratas-Vital J, et al. Olfactory mucosal autografts and rehabilitation for chronic traumatic spinal cord injury. Neurorehabil Neural Repair 2010;24:10-22.

46. Saberi H, Moshayedi P, Aghayan HR, et al. Treatment of chronic thoracic spinal cord injury patients with autologous Schwann cell transplantation: an interim report on safety considerations and possible outcomes. Neurosci Lett 2008;443:46-50.

47. Knoller N, Auerbach G, Fulga V, et al. Clinical experience using incubated autologous macrophages as a treatment for complete spinal cord injury: phase I study results. J Neurosurg Spine 2005;3:173-81.

48. Lammertse DP, Jones LA, Charlifue SB, et al. Autologous incubated macrophage therapy in acute, complete spinal cord injury: results of the phase 2 randomized controlled multicenter trial. Spinal Cord 2012;50:661-71.

49. Bradbury EJ, Carter LM. Manipulating the glial scar: chondroitinase $\mathrm{ABC}$ as a therapy for spinal cord injury. Brain Res Bull 2011;84:306-16.

50. Luo J, Borgens R, Shi R. Polyethylene glycol immediately repairs neuronal membranes and inhibits free radical production after acute spinal cord injury. J Neurochem 2002;83:471-80.

51. Das M, Patil S, Bhargava N, et al. Auto-catalytic ceria nanoparticles offer neuroprotection to adult rat spinal cord neurons. Biomaterials 2007;28:1918-25.

52. Harkema S, Gerasimenko Y, Hodes J, et al. Effect of epidural stimulation of the lumbosacral spinal cord on voluntary movement, standing, and assisted stepping after motor complete paraplegia: a case study. Lancet 2011;377:1938-47.

Affiliation: From the Department of Surgery (Wilson, Forgione, Fehlings), Division of Neurosurgery and Spinal Program, University of Toronto, Toronto, Ont.

Contributors: All of the authors contributed substantially to the conception and design of the study, to the drafting and critical revision of the article for important intellectual content and to the final approval of the published version.

Aknowledgement: Jefferson Wilson received postdoctoral fellowship support from the Christopher and Dana Reeve Foundation. 